
\title{
28 Research Suare \\ Effects of Different Silicate Minerals on Silicon Activation by Ochrobactrum sp. T-07-B
}

\section{Ying Lv ( $\nabla$ lvying940904@163.com )}

South-Central University for Nationalities https://orcid.org/0000-0003-3026-0498

Jia Li

South-Central University for Nationalities

\section{Zhenxing Chen}

South-Central University for Nationalities

Xingyu Liu

GRINM: General Research Institute for Nonferrous Metals

\section{Bowei Chen}

GRINM: General Research Institute for Nonferrous Metals

\section{Mingjiang Zhang}

GRINM: General Research Institute for Nonferrous Metals

\section{Xuan Ke}

South-Central University for Nationalities

\section{Tian C. Zhang}

University of Nebraska Omaha

\section{Research Article}

Keywords: electrolytic manganese residue, silicon-activating, Ochrobactium sp. T-07-B, silicate minerals, crystal structure

Posted Date: August 17th, 2021

DOI: https://doi.org/10.21203/rs.3.rs-775613/v1

License: (c) (1) This work is licensed under a Creative Commons Attribution 4.0 International License. Read Full License 


\section{Abstract}

As a kind of solid waste with a high silicon content, electrolytic manganese residue (EMR) can be utilized as silicon source by plants through bioleaching processes. EMR contains a variety of silicate minerals. In order to determine the source of available silicon in the bioleaching process of EMR, it is necessary to investigate the influence of silicate minerals in EMR on silicon-activating behavior of specific minerals. In this study, Ochrobactium sp. T-07-B was used to conduct bioleaching experiments on five kinds of silicate minerals with different structures (quartz, muscovite, biotite, olivine, and rhodonite); the growth of Ochrobactium sp. T-07-B, their acid- and polysaccharide-producing capacity, and evolution of surface morphology and structure of the silicate minerals in different systems were determined, so as to explore the silicon-activating capacity of Ochrobactium sp. T-07-B and the selectivity toward different minerals in the bioleaching process. Results showed that the effects of Ochrobactium sp. T-07-B for different silicate minerals were obviously different, and the sequence of silicon-activating efficiency from high to low was as follows: muscovite > biotite > rhodonite > olivine > quartz. Results of this study may be of guiding significance for the future research on the silicon-activating of solid waste.

\section{Highlights}

The crystal structure of silicate minerals influences the silicon-activating effect.

Ochrobactium sp. T-07-B is selective in different silicate minerals regarding silicon activation.

The growth and metabolic capacities of Ochrobactium sp. T-07-B are different.

\section{Introduction}

Silicon is an important element in plant growth and acts as an important mechanical and physical barrier during plant growth, especially under stress conditions (Huang et al., 2019; Wang et al., 2020; Yang et al., 2021). Electrolytic manganese residue (EMR) is a kind of industrial solid waste with a high silicon content, but most silicon exists in silicate minerals with very low water solubility; such, inactive silicon, cannot be directly absorbed and utilized by plants (Shu et al., 2020; Zhan et al., 2020). Therefore, it is very important to develop an efficient and environmentally friendly silicon-activating method for the reuse of silicon-containing solid waste.

At present, physical and chemical methods, such as chemical leaching, roasting, are traditional siliconactivating methods. Some researchers found that heat and saprolite composition might affect silicon availability in minerals (Schaller and Puppe, 2021). Studies have also shown that the dispersion of silicate minerals such as montmorillonite and wollastonite can be improved by cationic surfactants, coupling agents, polymer coating and other surface treatment (Wang et al., 2014). Other researchers also proposed that alkali excitation can effectively promote the silicon activation in minerals. For example, the activation rate of silicon can exceed $8 \%$ and $18 \%$ by muffle oven roasting and microwave roasting after adding alkaline sodium salts, respectively, which is significantly better than other methods (Jiang et al., 
2014; Peng et al., 2018). However, these traditional physical/chemical methods have many defects (high cost, high energy consumption, serious secondary pollution), thus, are of little practical application value (Li et al., 2018; Zhao et al., 2017).

Compared with the traditional physical and chemical processes, the bioleaching technology has the advantages of environmental friendliness, strong selectivity, low cost and energy consumption, mild reaction conditions, and can be implemented in large scale for industrial applications (Teng et al., 2018; Ye et al., 2020). Therefore, more and more attention has been paid to research and development of environmentally friendly and cost effective bioleaching technology for silicon activation, together with impurity removal, purification of raw ore, and the resource utilization of tailings. Many researchers have studied the silicon activation of silicate bacteria in mineral soil. For example, the leaching effect of Bacillus mucilaginosus on available silicon in EMR was studied (Chen et al., 2018), the leaching and decomposition behavior of bauxite by Bacillus circulans and Bacillus glia HJ07 was discussed (Sun et al., 2013b; Xiao et al., 2013), and the effect of potassium-solubilizing bacteria (CGMCC1.2411) on the desilication of potassium-rich shale was investigated (Man et al., 2015), etc.

In EMR, different silicate minerals have different crystal structures due to the different forms of siliconoxygen bonding mode (Man et al., 2015). Lv et al. (Lv et al., 2020) reported that the main silicate minerals in the EMR include frame quartz, layered muscovite and biotite, island olivine and chained rhodonite. The existing knowledge gaps are that, the interactions between bacteria and minerals as well as the associated mechanisms for and effects of silicon activation in a bioleaching process are unclear at all.

To fill these knowledge gaps, we used Ochrobactium sp. T-07-B to activate silicon from the aforementioned five different silicate minerals of the EMR. The specific objectives of this study were to investigate: 1) the effects of silicate mineral structures on bioleaching efficiency, silicon-activating ability, and associated metabolites of Ochrobactium sp. T-07-B; 2) changes in surface morphology and structure of the silicate minerals during the bioleaching process; and 3 ) the corresponding mechanisms of the bioleaching process.

\section{Materials And Methods}

\subsection{Materials}

\subsubsection{Silicate minerals}

The tested five silicate minerals were all purchased from China Geological Museum (Beijing, China). The quartz (diameter $(D)<0.150 \mathrm{~mm}$ ) was formed with a frame crystal structure; muscovite (with an average size of length $(L)=3.0 \mathrm{~cm}$, width $(W)=5.5 \mathrm{~cm}$, and height $(H)=0.1 \mathrm{~mm})$ and biotite $(L \times W \times H<3.5 \mathrm{~cm} x$ $7.0 \mathrm{~cm} \times 2.0 \mathrm{~cm})$ were formed with a layered crystal structure; and olivine $(\mathrm{D}=0.3 \mathrm{~cm})$ and rhodonite $(\mathrm{L} x$ $\mathrm{W} \times \mathrm{H}<3.0 \mathrm{~cm} \times 3.5 \mathrm{~cm} \times 2.0 \mathrm{~cm}$ ) had an island and chained crystal structure. The total silicon in muscovite, biotite, olivine and rhodonite was about $45 \mathrm{wt} \%$, while $90 \mathrm{wt} \%$ in quartz (Lv et al., 2020). The 
samples were dried in an electrothermal blowing drying oven (101-2AB, Tianjin Tester Instrument Co. Ltd., China) at $105^{\circ} \mathrm{C}$ for $24 \mathrm{~h}$, ground with a pulverizer (LINGSUM, China) and screened with a Nylon mesh (100 mesh, Shangyu Shenchao Instrument, China) to make the sample particles evenly distributed and ready for use in the bioleaching tests.

\subsubsection{Strain: Ochrobactium sp. T-07-B}

The strain used in this study was Ochrobactium sp. T-07-B, which was selectively isolated from the soil around the EMR stock. The culture medium used for the strain isolation from the soil mineral sample was Alexander Rove medium: sucrose $5.0 \mathrm{~g}, \mathrm{Na}_{2} \mathrm{HPO}_{4} 2.0 \mathrm{~g}, \mathrm{MgSO}_{4} \cdot 7 \mathrm{H}_{2} \mathrm{O} 0.5 \mathrm{~g}, 5 \mathrm{~g} \cdot \mathrm{L}^{-1} \mathrm{FeCl}_{3} 1 \mathrm{~mL}, \mathrm{CaCO}_{3}$ $0.1 \mathrm{~g}$, soil mineral sample $1.0 \mathrm{~g}$, distilled water $1000 \mathrm{~mL}$, AGAR $15-20 \mathrm{~g}, \mathrm{pH} 7.0-7.2$. The sterilization condition was $121^{\circ} \mathrm{C}$ for $30 \mathrm{~min}$. The isolated Ochrobactium sp. T-07-B bacteria were preserved in the South-Central University for Nationalities (Wuhan, China) and used after regrowth in a sterilized batch reactor.

\subsection{Bioleaching experiments}

All tests were conducted (as shown in Fig. 1) with three replicates $(n=3)$; the average and standard deviations were report here.

Firstly, $100 \mathrm{~mL}$ liquid medium was added into a $250 \mathrm{~mL}$ conical flask, and then $5 \mathrm{~g}$ of each of the five different minerals were added into the flask as leaching substrates. After that, the bacteria solution in a logarithmic growth phase was inoculated with the initial concentration of Ochrobactium sp. T-07-B in the

bioleaching system was about $10^{6} \mathrm{cell} \cdot \mathrm{mL}^{-1}$, while flasks of control tests were not inoculated with bacteria at all. The $\mathrm{pH}$ and temperature of the system were adjusted to $7.0-7.2$ and $30^{\circ} \mathrm{C}$. The flasks were shanked with a thermostatic oscillator (THZ-92B, Changzhou Jintan Jingda Instrument Manufacturing Co., Ltd., China) at a rotation speed of $180 \mathrm{rev} \cdot \mathrm{min}^{-1}$. During the bioleaching tests, the flask was taken out from the shaker, and after 30 min sedimentation (allowing for the mineral particles settled but bacterial and available silicon content still in the solution), the supernatant $(5 \mathrm{~mL})$ of the bioleaching solution was sampled every $48 \mathrm{~h}$ for measurement of the bacterial concentration, $\mathrm{pH}$, viscosity and concentration of available silicon in the leaching solution. Then, a same volume of medium solution was added to the bioleaching system. The experiment ended when the concentration of available silicon reached the peak and stabilized.

\subsection{Characterization}

The available silicon in the leaching solution was determined by the silico-molybdenum blue method(Duan and Shi, 2015). The chemical composition of the five silicate minerals was determined by an X-ray fluorescence spectrometer (XRF) (Axios Advanced, PAnalytical, Netherlands). An X-Ray Diffraction (XRD) (D8 ADVANCE, BRUKER Corporation, Germany) was used to determine the phase composition of the five silicate minerals with or without bioleaching. A scanning electron microscope (SEM) (HITACHI UHR FE-SEM SU8000 Series, Japan) was used to observe the morphology of silicate minerals with different crystal structures. 


\section{Results And Discussion}

\subsection{Growth of Ochrobactium sp. T-07-B in different systems}

Figure 2 shows that the strain had the similar growth trend in different minerals: the bacterial concentration began to increase rapidly after the second day and reached the peak on the tenth day. However, the specific biomass values in different systems varied significantly. During the whole bioleaching process, the bacterial growth in the layered muscovite and biotite groups was the best, and the biomass concentration of the two minerals was always higher than that of the other three minerals. The bacterial concentration in the frame quartz group was the lowest. These outcomes indicated that the growth of Ochrobactium sp. T-07-B in minerals with different crystal structures was significantly different.

\subsection{Production of acidic and polysaccharides in different systems}

In our previous study, it was found that the bacterial strains were accompanied by the production of acidic metabolites and polysaccharides in the process of bioleaching(Lv et al., 2019); thus, these two indicators could be used to assist in judging the growth of microorganisms in the system. Therefore, we simultaneously measured the $\mathrm{pH}$ and viscosity of the systems in the bioleaching process to measure the acid-producing and polysaccharide-producing capacity of Ochrobactium sp. T-07-B, respectively, and the results are shown in Figs. 3 and 4.

As can be seen from Fig. 3, Ochrobactium sp. T-07-B could produce acid in all groups of the five silicate minerals, but the acid production capacity of the strain was affected by different minerals. As a general trend, the $\mathrm{pH}$ of the leaching solution rapidly decreased after the start of the bioleaching process, reached the lowest value around day 10 in the five groups, and then began to rise gradually after day 10 . Figure 3 shows that the acid-producing capacity of the culture system was the strongest (with the lowest pH being about 4.75) for the muscovite and biotite minerals, followed by the olivine and rhodonite system (with the lowest $\mathrm{pH}$ being about 5.25), and the weakest (with the lowest $\mathrm{pH}$ being about 5.80 ) for the quartz system.

Figure 4 shows that all groups had the same viscosity trend, i.e., increasing slowly in the first four days, increasing rapidly in days 6 to 10, and then maintaining stable after day 10. Specifically, the viscosity of the leaching solution at day 10 was the highest (up to $412 \mathrm{MPa} \cdot \mathrm{s}$ ) in the muscovite system, followed by that of the biotite system (405 MPa.s) and then the olivine and rhodonite systems (about $370 \mathrm{MPa} \cdot \mathrm{s}$ ), and was the lowest (just about $290 \mathrm{MPa} \cdot \mathrm{s}$ ) in the quartz system.

Combining the results shown in Figs. 2 to 4 , one can observe the influence of different silicate minerals on the relationships among bacterial growth, $\mathrm{pH} / \mathrm{viscosity}$ changes, and acids/polysaccharides production. Between days 0 to 2, slow growth of Ochrobactium sp. T-07-B (Fig. 2) resulted in moderate production of acid and polysaccharides and relative smaller changes in pH and viscosity (Figs. 3 and 4). 
During days 4 to 10, with the rapid growth of bacteria in the leaching systems (Fig. 2), Ochrobactium sp. T-07-B metabolized and produced a large amount of acids and extracellular polysaccharides, resulting in rapid changes in $\mathrm{pH}$ and viscosity of the leaching solutions. After day 10 , the biomass decreased with time, together with an increase in the system $\mathrm{pH}$, presumably due to the consumption of substrates/nutrients in the leaching systems leading to reduced acid production rates. Meanwhile, after day 10 , the systems either more or less kept their extracellular polysaccharide plateaus in the muscovite, biotite, and quartz systems or slightly reduced their viscosities in the olivine and rhodonite systems, indicating that polysaccharides' production were still occurring and outcompeted their degradation rates by the bacteria. According to the results in Figs. 2 to 4, Ochrobactium sp. T-07-B was more likely to grow in the bioleaching system of muscovite and biotite with a stronger capacity to produce acids and exopolysaccharides, followed by the olivine and rhodonite systems with little difference between these two systems, and slowly grew with a moderate capacity to produce acids and exopolysaccharides in the quartz system. Therefore, it can be concluded that different silicate minerals do have strong influence on the growth and metabolic capacity of Ochrobactium sp. T-07-B.

\subsection{Silicon-activating effects in different systems}

Figure 5 shows that the five systems had an overall consistent trend in silicon activation: gradually increasing to the maximum during the initial ten days and then staying in the plateaus after day 10 , presumably due to the consumption of substrates/nutrients with time in the leaching systems. The control groups showed very limited silicon-activating capacity $\left(\leq 5 \mathrm{mg} \cdot \mathrm{L}^{-1}\right)$ with no time-based fluctuation at all, indicating that the content of available silicon in the raw minerals was very low, and the pure (bacteria-free) medium solution had no effect on silicon activation from the five minerals.

Comparison of the data between the bioleaching and control systems in Fig. 5 indicates the necessity of adding Ochrobactium sp. T-07-B for silicon bioleaching, and that, the silicon activation in the five silicate minerals was all derived from the metabolism of Ochrobactium sp. T-07-B. Out of the five groups, Ochrobactium sp. T-07-B had the best activation effect on muscovite and biotite, followed by olivine and rhodonite, and the worst on quartz. Specifically, the content of available silicon at day 10 was up to 23.63 , $65.84,63.84,55.76$ and $50.98 \mathrm{mg} \cdot \mathrm{L}^{-1}$ in the quartz, muscovite, biotite, olivine and rhodonite systems, respectively. These experimental results were consistent with the change in bacterial concentration and acid/polysaccharide-producing capacity shown in Figs. 2 to 4, that is, the higher the metabolic activity of Ochrobactium sp. T-07-B, the higher the silicon-activating efficiency in the system. Accordingly, the changes of the relevant physical and chemical properties in the bioleaching system followed the following order: muscovite > biotite > rhodonite > olivine > quartz. Combined with the specific crystal structure of different silicate minerals to evaluate, the influence of silicate minerals on silicon activation in a bioleaching system followed the following order: layered $>$ chained $>$ island $>$ frame, wherein all the properties of the two layered minerals showed great similarity.

\subsection{Changes of mineral phases and surface morphology 3.4.1 XRD patterns of different silicate minerals}


XRD patterns of raw and bioleached minerals revealed the mineral phase changes of silicate minerals with or without bioleaching effect. Figure 6a shows that the purity of quartz was quite high in raw mineral, and only the very low kurtosis associated with pyroxene was found in the control group. In addition, the mineral structure did not change significantly even after the bioleaching of Ochrobactium sp. T-07-B. On the whole, the characteristic peaks of frame quartz in the two groups were clear and strong, and the whole peak shape had no obvious change. In other four silicate minerals, quartz was also observed. The prevalence of quartz might be due to the fact that it is one of the most widely distributed minerals on the surface of the Earth and is a component of many rocks and deposits. Figure 6 shows that the characteristic peaks of muscovite (Fig. 6b) and biotite (Fig. 6c) had been significantly reduced or even disappeared, which indicated that Ochrobactium sp. T-07-B had a good selectivity for siliconactivating of silicate minerals with a layered structure since both muscovite and biotite minerals have a layered structure. Figure 6 shows that the characteristic peaks of olivine (Fig. $6 \mathrm{~d}$ ) and rhodonite (Fig. 6e) also showed a trend of decrease, but such decreases were weaker than those shown in Figs. $6 \mathrm{~b}$ and $6 \mathrm{c}$. Considering the crystal structure characteristics of olivine and rhodonite, the XRD patterns showed that Ochrobactium sp. T-07-B had a moderate (if not limited) silicon-activating efficiency for the silicate minerals with chained and island structures. These results support the bioleaching effects of Ochrobactium sp. T-07-B on different silicate minerals shown in Fig. 5.

\subsubsection{SEM spectrums of different silicate minerals}

In order to directly understand the surface morphology changes of different silicate minerals in the bioleaching process, the five silicate minerals (including both the control and bioleaching groups) were filtered after leaching tests, then dried and ground for SEM analyses. Figure 7 shows that a clear and complete crystal structure could be observed in the control groups, while the mineral surfaces of the bioleaching groups presented obvious changes: the original crystal structure of the silicate mineral was destroyed; the initial layered or block structure disappeared and became a rough and irregular structure; and the larger particles were broken into smaller ones. Obviously, a large number of flocculating structures appeared on the mineral surface after bioleaching.

Specifically, Ochrobactium sp. T-07-B had obvious dissolution effect on muscovite and biotite as the two raw minerals without bioleaching (Figs. 7c and 7e) had smooth surface, almost intact particles, and shape outline and edges. After bacterial action by Ochrobactium sp. T-07-B, the two mineral particles (Figs. 7d and 7f) became smaller; the surface was uneven; and the particles became rounded, and especially the changes of the raw cracks and bulges were more obvious. The mineral morphology of olivine (Figs. 7g and 7h) and rhodonite (Figs. 7i and 7j) did not change greatly. The cracks in the raw minerals became unsharp, and the contours were more blurred than that of the control groups. However, the surface morphology of quartz (Figs. 7a and 7b) showed almost no change in the control and bioleaching groups because quartz has a frame structure of silicate minerals, in which the Si-O bond is very stable and difficult to destroy. Relatively, olivine with a chained structure, rhodonite with an island structure and muscovite/biotite with a layered structure were more easily to be destroyed than quartz, allowing microbes to interact with these minerals for biological enhanced silicon activation. Therefore, 
when Ochrobactium sp. T-07-B decomposes silicate minerals, it will give priority to the part of mineral crystal structure that is easier to be destroyed, and it will absorb and grow on mineral surface through the complexing ability of extracellular polysaccharide production, then resulting in mineral decomposition and weathering through acid production. Similarly, the changes of surface morphology of different silicate minerals also had a sequence: the SEM spectra of the layered muscovite and biotite showed the most obvious changes, followed by the chained rhodonite, then the olivine with an island structure, and finally the frame-structured quartz with almost no change.

\subsection{Discussions and Implications}

Results obtained from this study are consistent with previous studies, confirming that bacterial silicon activation is related to the acidic metabolites and polysaccharides produced by the bacteria metabolism in the system (Chen, 2019; Lv et al., 2019; Ma, 2010). From the mechanistic point of view, the side chains of polysaccharides released by bacteria are rich in $\mathrm{O}-\mathrm{H}$ with strong adsorption capacity, which can adsorb the free silicate minerals in the bioleaching system, so as to form "bacteria-silicate mineral complex" (Zhong et al., 2013); the organic acids in the metabolites and the inorganic acids (generated from the decomposition of organic acids) may dissolve and decompose silicate minerals through contact and react with mineral particles (Lv et al., 2019; Sun et al., 2012). In addition, the organic acids (mainly including oxalic, citric, gluconic, lactic, formic, and acetic acids) and amino acids in the bacterial metabolites could be hydrolyzed to form an acidic solution, which then directly dissolved silicate minerals (Sun et al., 2013a). In summary, the XRD patterns shown in Fig. 6 indicate that the higher the siliconactivating effect on silicate mineral, the more obvious changes of mineral phase would be observed, which further illustrate that Ochrobactium sp. T-07-B has certain selectivity in the silicon-activating effect toward minerals with different crystal structures.

On the other hand, results of this study indicate that the crystal structure of silicate minerals play a decisive role in silicon activation. the influence of silicate minerals on silicon activation in a bioleaching system followed the following order: layered $>$ chained $>$ island $>$ frame. These outcomes are consistent with the results of the bioleaching of silicate minerals with Paenibacillus mucilaginosus in our previous study (Lv et al., 2020). The minerals that are more difficult to decompose would have less components available for bacteria to utilize, be worse for the growth of Ochrobactium sp. T-07-B and prohibit the bacterial form effective activating of silicon in the minerals.

This study shows that the bioleaching effect of Ochrobactium sp. T-07-B for different silicate minerals is obviously different. Once knowing the specific silicate mineral composition in solid wastes, one can evaluate the possibility of bioleaching by Ochrobactium sp. T-07-B to maximize resource utilization. For example, the total silicon in muscovite, biotite, olivine and rhodonite was about $45 \mathrm{wt} \%$, while $90 \mathrm{wt} \%$ in quartz, then $65.84,63.84,55.76,50.98$ and $23.63 \mathrm{mg} \cdot \mathrm{L}^{-1}$ available silicon was obtained in the bioleaching system for five silicate minerals, respectively. However, quartz is shown in all panels as mineralization of the silicate minerals might have occurred in these samples. Therefore, we first need to quantitatively calculate the silicon activation efficiency corresponding to pure silicate minerals (that is, 
the activation effect caused by quartz should be removed from the other four minerals), and the activation efficiency of quartz, muscovite, biotite, olivine and rhodonite is denoted as $A \%, B \%, C \%, D \%$ and $\mathrm{E} \%$, respectively. Then, for a solid waste containing $\mathrm{F} \%, \mathrm{G} \%, \mathrm{H} \%, \mathrm{l} \%$ and $\mathrm{J} \%$ of these five silicate minerals, it can be speculated the silicon activation efficiency derived from these five silicate minerals by Ochrobactium sp. T-07-B according to the following formula: $\mathrm{A} \% \times \mathrm{F} \%+\mathrm{B} \% \times \mathrm{G} \%+\mathrm{C} \% \times \mathrm{H} \%+\mathrm{D} \% \times 1 \%+$ $\mathrm{E} \% \times \mathrm{J} \%$. Therefore, results of this study may be used for guiding future research on the silicon-activating of solid waste.

\section{Conclusion}

The crystal structure of silicate minerals plays a decisive role in silicon bio-activation. As a highly effective silicon-activating bacterial feed, Ochrobactium sp. T-07-B showed different growth and metabolic abilities in bioleaching systems of five silicate minerals with different crystal structures. Ochrobactium sp. T-07-B showed a better silicon-activating effect on layered muscovite and biotite than on chained olivine and island rhodonite, while the weathering effect of quartz with frame structure was the worst. In addition, the results of XRD patterns and SEM spectra also show more obvious changes in the bioleaching system with better activation efficiency of silicon. Results of this study may be of guiding significance for the future research on the silicon-activating of solid waste to realize more efficient utilization and reuse of resources.

\section{Declarations}

\section{Acknowledgments}

We thank South-Central University for Nationalities and National Engineering Laboratory of Biohydrometallurgy, GRINM Group Corporation Limited, China, for their support during the experiments.

\section{Authors' contributions}

Jia Li provided the idea of this work. Ying Lv and Zhenxing Chen performed the experiments, collected samples, detected and analyzed the data. Ying Lv and Xuan Ke prepared the figures, and wrote the manuscript. Ying Lv and Zhenxing Chen detected physiochemical properties. Xingyu Liu, Bowei Chen, Mingjiang Zhang and Tian C. Zhang were involved in experimental design. Tian C. Zhang revised the manuscript. All authors contributed to the article and approved the submitted version.

\section{Funding}

This project is financially supported by the National Natural Science Foundation of China (grant numbers $51804354,51974279)$, the National Key Research \& Development Program of China [grant numbers 2018YFC18018, 2018YFC18027], KeJunPing [2018] No. 159, the Guangxi Scientific Research and Technology Development Plan [grants number GuikeAB16380287 and GuikeAB17129025], GRINM Science and Development [grants number2020 No 75], which are greatly appreciated. 


\section{Data availability}

The datasets used and/or analyzed during the current study are available from the corresponding author on reasonable request.

\section{Compliance with ethical standards}

Ethical approval Not applicable

Consent to publish Not applicable

Competing interests The authors declare that they have no competing interests.

\section{References}

Chen, Z, 2019. Isolation of silicate activating bacteria and its activation of effective silicon in electrolytic manganese slag, Wuhan. South-Central University for Nationalities.

Chen, Z, Li, J, Du, D, Ye, H, Lan, J, Lv, Y, 2018. Study on Activation of Effective Silicon in Electrolytic Manganese Slag by Silicate Bacteria. BULLETIN OF THE CHINESE CE囚AMIC SOCIETY 37:3581-3586.

Duan, W, Shi, L, 2015. Determination of availabe silica content in silicon fertilizer by Molybdenum Blue Spectrophotometry. Journal of Analytical Science 31:389-392.

Huang, H, Rizwan, M, Li, M, Song, F, Zhou, S, He, X, Ding, R, Dai, Z, Yuan, Y, Cao, M, Xiong, S, Tu, S, 2019. Comparative efficacy of organic and inorganic silicon fertilizers on antioxidant response, $\mathrm{Cd} / \mathrm{Pb}$ accumulation and health risk assessment in wheat (Triticum aestivum L.). Environ Pollut 255:113146.

Jiang, M, Du, Y, Du, D, Deng, Y, Chen, N, 2014. Technology for Producing Silicon-manganese Fertilizer from EMM 『esidue. China's Manganese Industry 32:16-19+24.

Li, J, Du, D, Peng, Q, Wu, C, Lv, K, Ye, H, Chen, S, Zhan, W, 2018. Activation of silicon in the electrolytic manganese residue by mechanical grinding-roasting. Journal of Cleaner Production 192:347-353.

Lv, Y, Li, J, Ye, H, Du, D, Li, J, Sun, P, Ma, M, Wen, J, 2019. Bioleaching behaviors of silicon and metals in electrolytic manganese residue using silicate bacteria. Journal of Cleaner Production 228:901-909.

Lv, Y, Li, J, Ye, H, Du, D, Sun, P, Ma, M, Zhang, T C, 2020. Bioleaching of silicon in electrolytic manganese residue (EMR) by Paenibacillus mucilaginosus: Impact of silicate mineral structures. Chemosphere 256:127043.

Ma, J, 2010. Isolation and identification of extracellular polysaccharides producing bacteria. Anhui University 
Man, L, Xiao, G, Zhang, X, Sun, D, 2015. Bioleaching of bauxite by silicate bacteria and change of bacterial community structure during leaching process. Journal of Central South University(Science and Technology) 46:394-403.

Peng, Q, Li, J, Du, D, Ye, H, 2018. Optimization of Microwave Activated Effective Silicon Process Conditions for Electrolytic Manganese \esidue by \esponse Surface Methodology. BULLETIN OF THE CHINESE CE囚AMIC SOCIETY 37:2548-2554.

Schaller, J, Puppe, D, 2021. Heat improves silicon availability in mineral soils. Geoderma 386.

Shu, J, Li, B, Chen, M, Sun, D, Wei, L, Wang, Y, Wang, J, 2020. An innovative method for manganese $(\mathrm{Mn}(2+))$ and ammonia nitrogen ( $\mathrm{NH} 4(+)-\mathrm{N})$ stabilization/solidification in electrolytic manganese residue by basic burning raw material. Chemosphere 253:126896.

Sun, D, Chen, Y, Cao, F, 2012. Effects of mineral environments on desilicon from bauxite by silicate bacteria. Chemical Engineering Journal 31:2341-2347.

Sun, D, Chen, Y, Cao, F, 2013a. Influence of microbe-mineral contact medol on decomposition of bauxite. Journal of China University of Mining \& Technology 42:122-128.

Sun, D, Wang, H, Zhang, Q, 2013b. Effects of Bacillus circulans on decomposition behavior of bauxite. The Chinese Journal of Nonferrous Metals 23:1119-1128.

Teng, Q, Feng, Y, Li, H, 2018. Effects of silicate-bacteria pretreatment on desiliconization of magnesite by reverse flotation. Colloids and Surfaces A: Physicochemical and Engineering Aspects 544:60-67.

Wang, B, Chu, C, Wei, H, Zhang, L, Ahmad, Z, Wu, S, Xie, B, 2020. Ameliorative effects of silicon fertilizer on soil bacterial community and pakchoi (Brassica chinensis L.) grown on soil contaminated with multiple heavy metals. Environ Pollut 267:115411.

Wang, J, Sun, Z, Zhu, B, Yu, C, 2014. Research Progress of Polypropylene /silicate Composites. BULLETIN OF THE CHINESE CE囚AMIC SOCIETY 33:1700-1705.

Xiao, G, Dai, J, Sun, D, 2013. Effects of biofilm and passivation coating forming on bacterial desilicon from bauxite. Journal of China University of Mining \& Technology 42:824-831.

Yang, L, Jiangnan, T, Jian, D, Shili, Z, Yinghong, W, 2021. Preparation of silicon-potassium fertilizer from low-iron red mud of Bayer process and silicon-potassium activation mechanism. Journal of Wuhan University of Science and Technology 44:27-33.

Ye, M, Liang, J, Liao, X, Li, L, Feng, X, Qian, W, Zhou, S, Sun, S, 2020. Bioleaching for detoxification of waste flotation tailings: Relationship between EPS substances and bioleaching behavior. J Environ Manage 279:111795. 
Zhan, X, Wang, L, Wang, L, Gong, J, Wang, X, Song, X, Xu, T, 2020. Co-sintering MSWI fly ash with electrolytic manganese residue and coal fly ash for lightweight ceramisite. Chemosphere 263:127914.

Zhao, J, Wu, W, Zhang, X, Zhu, M, Tan, W, 2017. Characteristics of bio-desilication and bio-flotation of Paenibacillus mucilaginosus BM-4 on aluminosilicate minerals. International Journal of Mineral Processing 168:40-47.

Zhong, C, Xiao, G, Cao, F, Sun, D, 2013. Orientation Screening and Desilicon Abilities of Silicon-releasing Microorganisms from Bauxite. Geological Journal of China Universities 19:692-699.

\section{Figures}

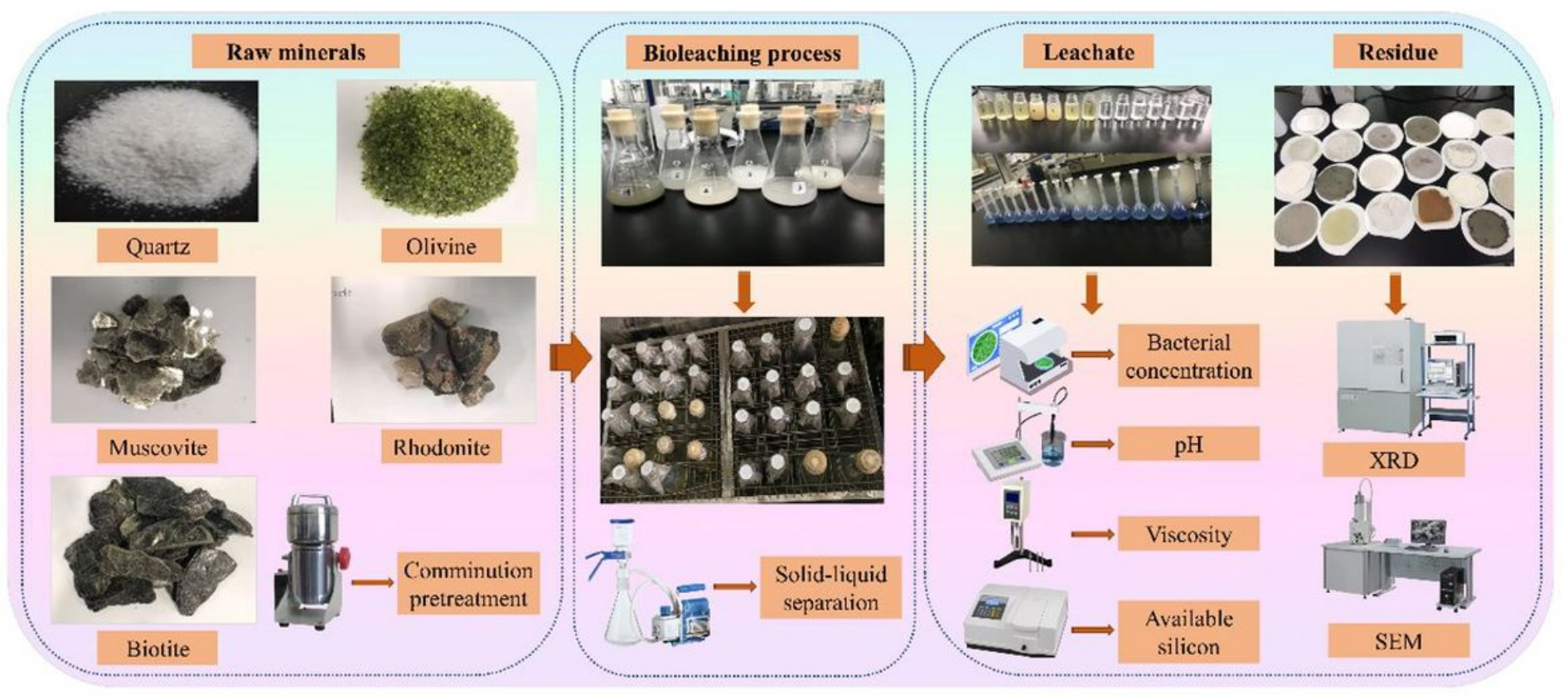

\section{Figure 1}

Diagram of experimental design and arrangement. 


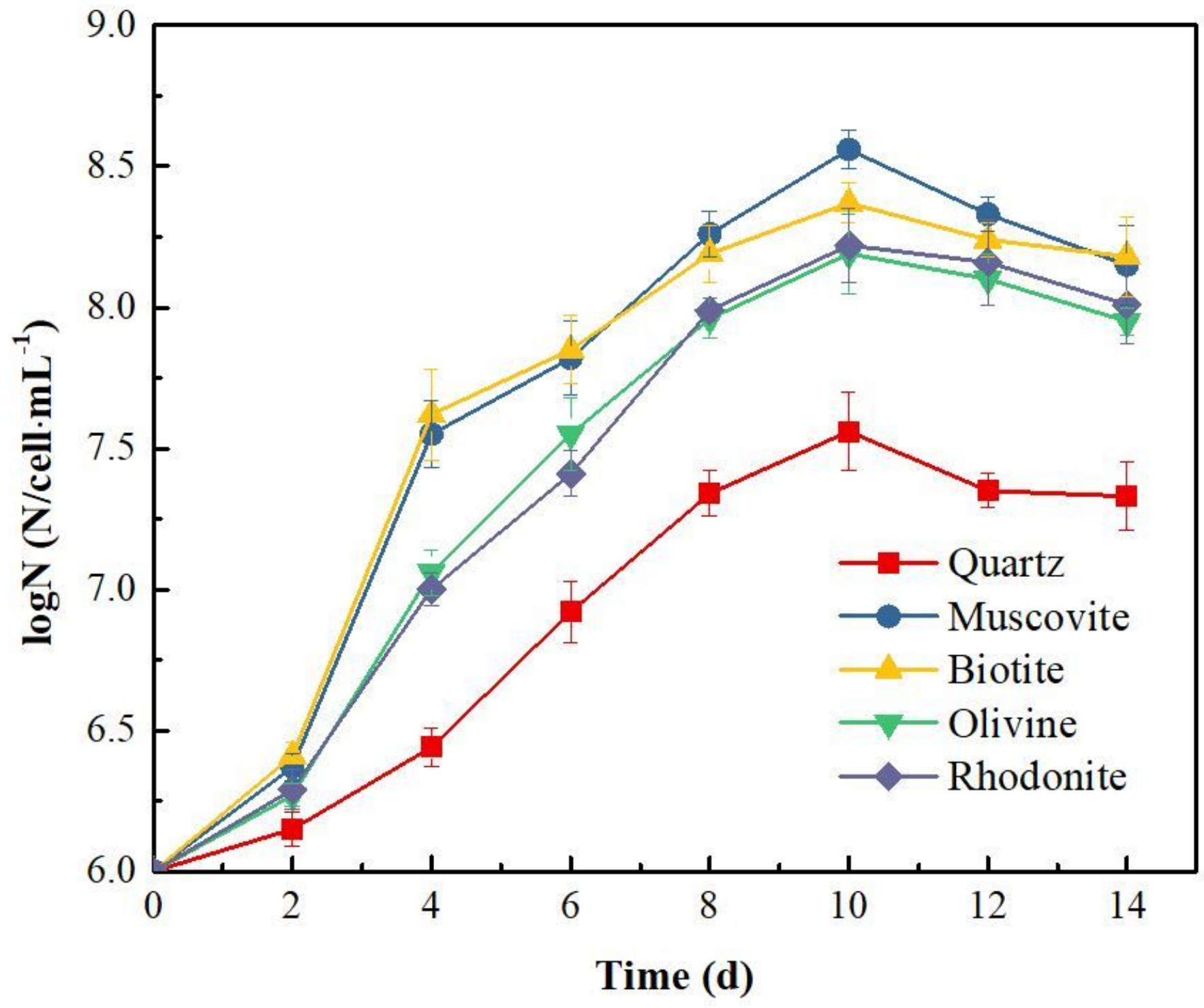

Figure 2

Bacterial concentration of Ochrobactium sp. T-07-B in different systems. 


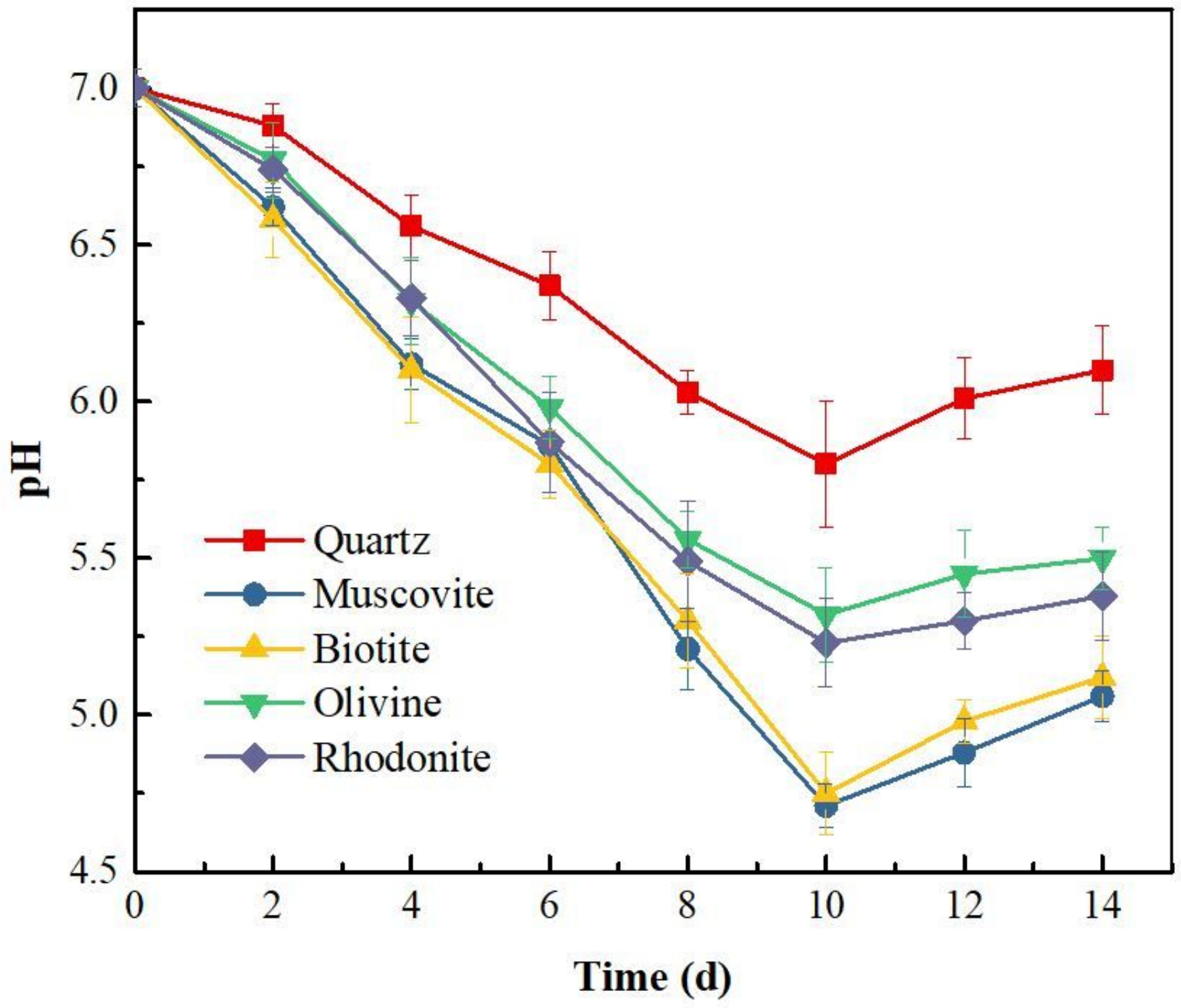

Figure 3

Influence of different minerals on time courses of $\mathrm{pH}$ of bioleaching solutions. 


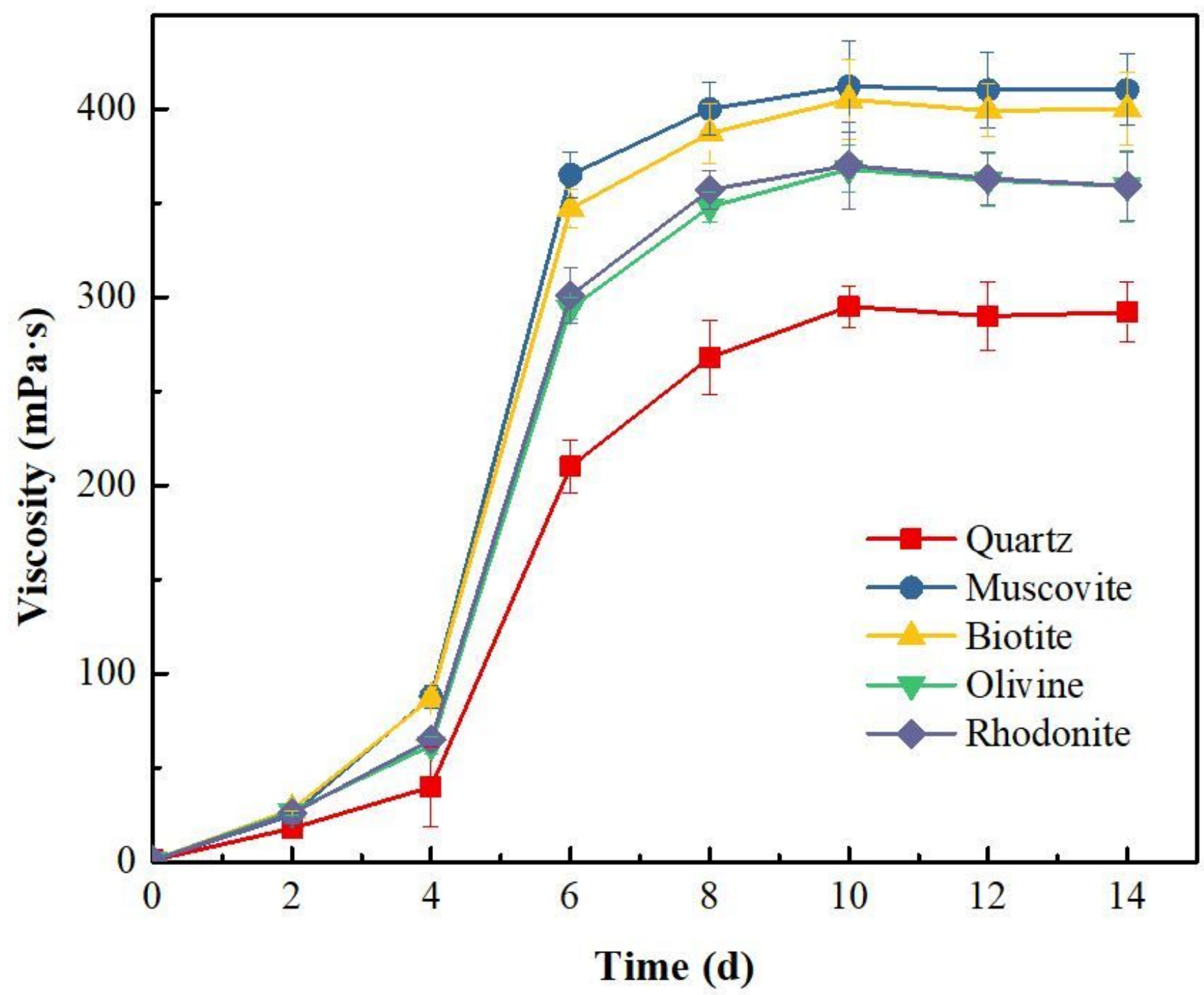

Figure 4

Influence of different minerals on time courses of viscosity of bioleaching solutions. 


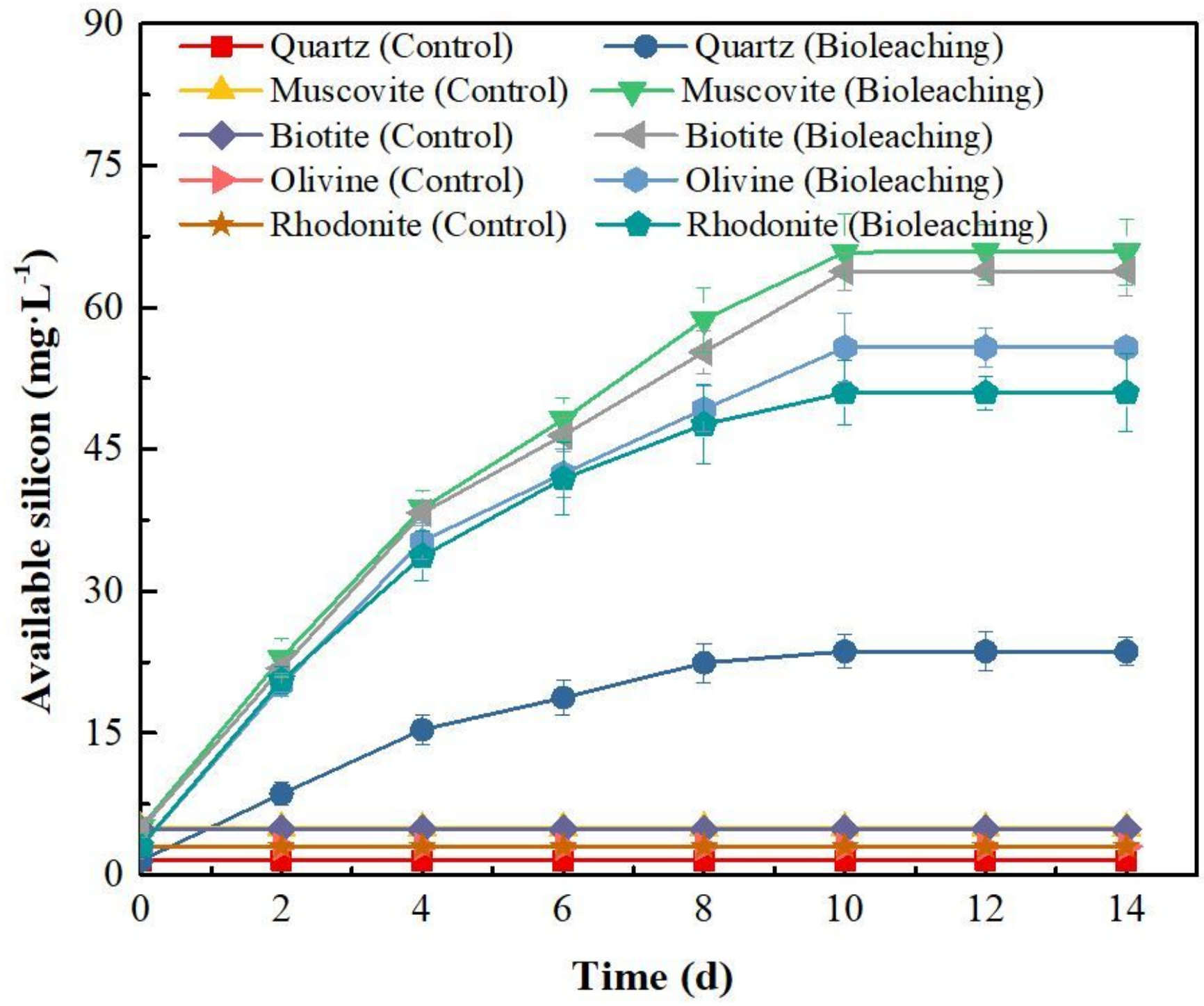

Figure 5

Influence of different minerals on time courses of available silicon in the bioleaching systems. 

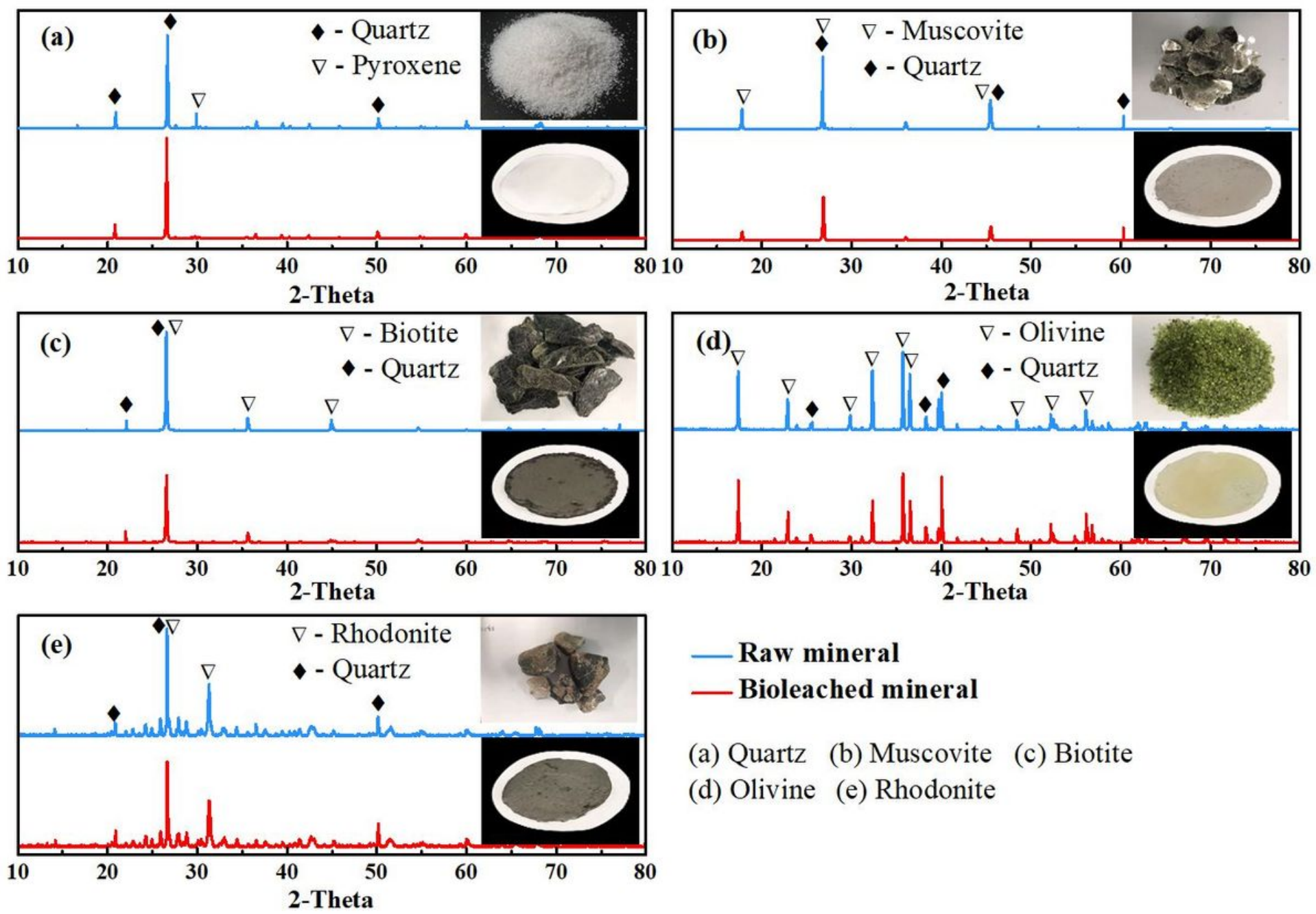

_ Raw mineral

— Bioleached mineral
(a) Quartz
(b) Muscovite
(c) Biotite
(d) Olivine
(e) Rhodonite

Figure 6

XRD patterns of different silicate minerals with or without bioleaching. 

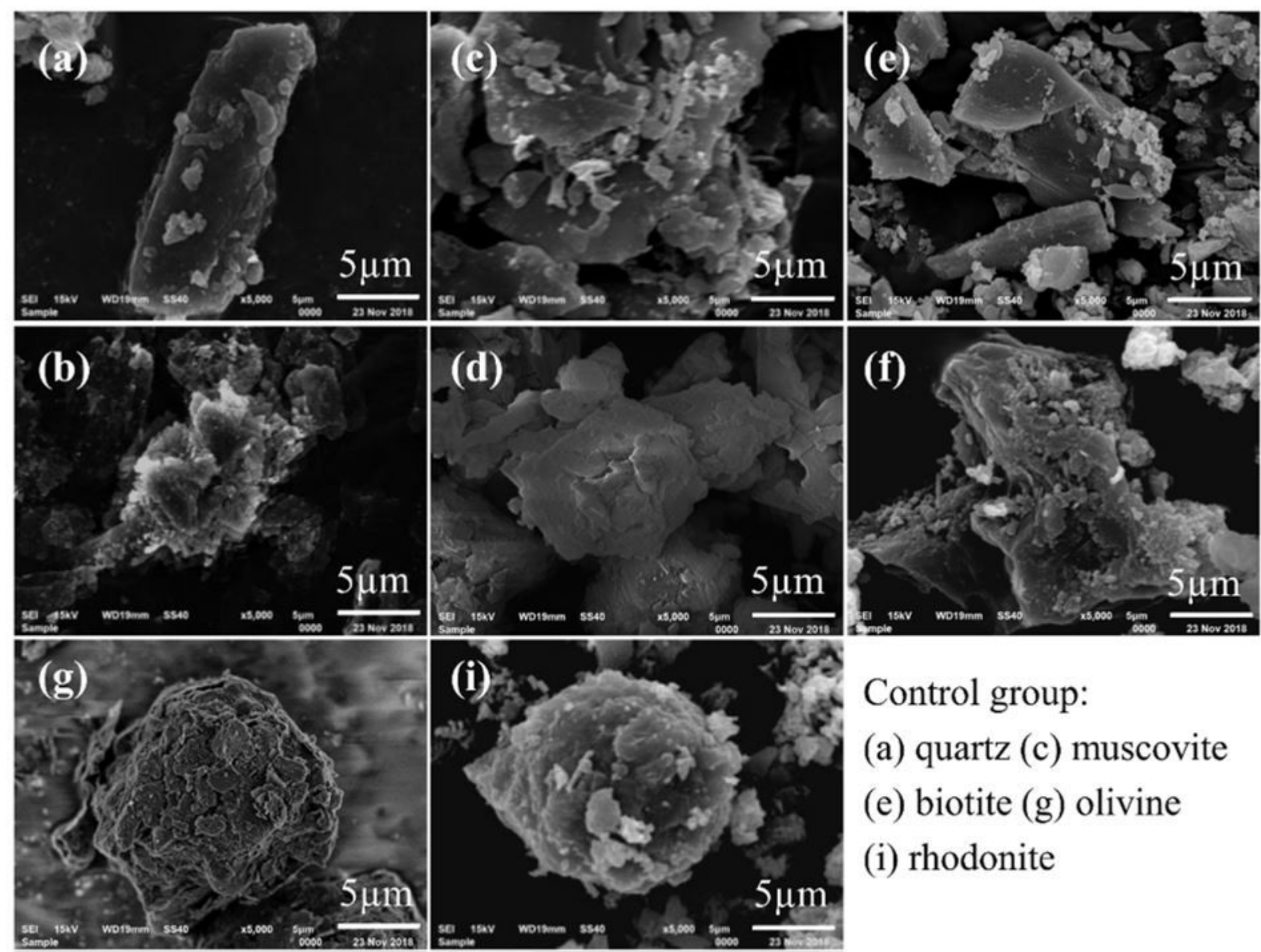

Control group:

(a) quartz (c) muscovite

(e) biotite (g) olivine

(i) rhodonite
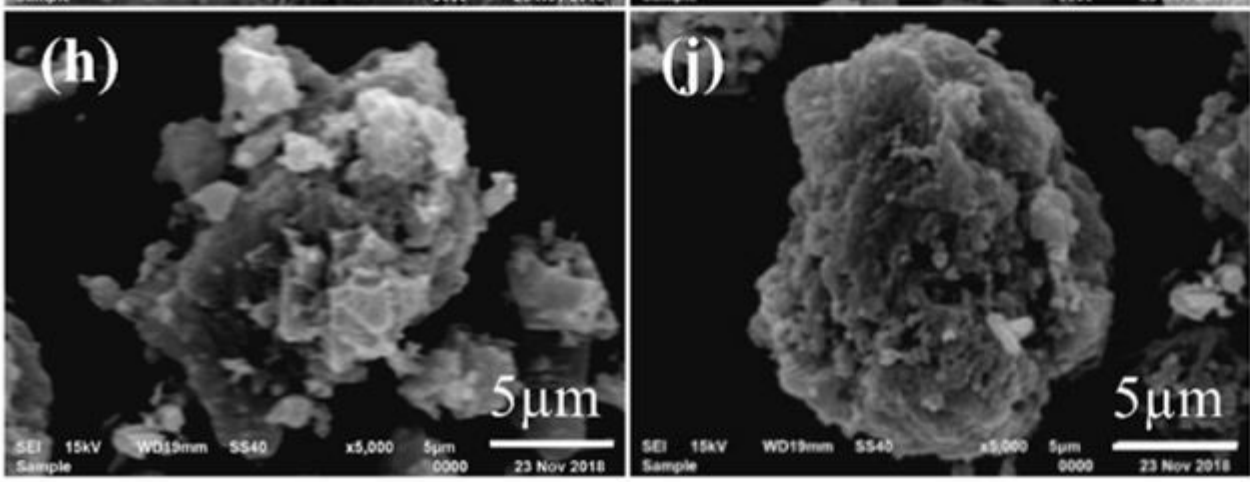

Bioleaching group:

(b) quartz (d) muscovite

(f) biotite (h) olivine

(j) rhodonite

Figure 7

SEM spectra of different silicate minerals with or without bioleaching.

\section{Supplementary Files}

This is a list of supplementary files associated with this preprint. Click to download. 
- graphicsabstract.jpg

Page 19/19 